\title{
Using Qualitative Data Analysis Software to Support Learning and Teaching of Research Practices
}

\author{
Kikooma Julius \\ School of Psychology, Makerere University, Uganda
}

\begin{abstract}
In many universities and research institutions in Africa, there is a sense of growing frustration among social science scholars on the continent regarding the lack of good materials available in (and from) their context for teaching qualitative methods that successfully blend technology and methodology. This paper reflects upon the challenges and opportunities for integrating qualitative data analysis software in methodology classes and the implication for preparing new qualitative researchers for future roles.
\end{abstract}

\section{Introduction}

It can be said that while the tools for research have taken advantage of technological advances, teaching in qualitative methods has not kept up with the pace. In the social science community in Africa, this seems to stem from a number of causes. First, existing staff- many of whom are well educated in qualitative methodology - received their training before software tools became widely available. Second, there seems to be a missing critical mass of people focused on teaching the craft of qualitative analysis [1] [2]. In addition, there seems to be a reticence to use qualitative software tools as well as a growing sense of frustration with the lack of good materials available for teaching qualitative methods with the 'modern' tools at our disposal. Either way, this inability to use tools has meant that new scholars have either had to learn on their own or take advantage of the relatively limited training opportunities provided by commercial trainers. In fact the demand for training workshops in the use of Computer Assisted Qualitative Data analysis Software (CAQDAS) is rapidly growing among qualitative researchers and indeed some program developers travel widely to lead one-day or two-day workshops. But there are increasing concerns that these workshops could lead to a misleading use of software programs as tools to assist qualitative analysis and, as a consequence, the undertaking of qualitative research projects in which the qualitative methodology has been replaced or imposed by the software. Thus, while there is wide acceptance now that software should probably be used to manage large qualitative data sets, a lack in local support means that researchers-in-the-making do not get enough guide or practice in using technology. As Johnstone observed, this has the consequence that project design and software use are often tacked together in an inefficient way to the detriment of outcome [5].

Against the above background, the focus of this paper is to reflect upon the challenges and opportunities for integrating qualitative data analysis software in methodology classes and the implication for preparing new qualitative researchers for future roles in a variety of fields. In my work with students and researchers in South Africa and Uganda, I have come to realize that the following issues require careful and peculiar considerations by the instructor:

- Qualitative research design using Qualitative Data Analysis Software (QDAS)

- Blending technology and methodology

- Alternatives when teaching and learning CAQDAS

- Collaborative working

Discussions on the above issues draw on my experience in combining methodological and technological elements in short term training although much is yet to be discovered about applying these ideas to the classroom setting over a longer period of time.

\section{Qualitative research design using CAQDAS}

It has been observed that teaching qualitative methodology to future researchers is a challenging art [3]. Typically, instruction occurs prior to engagement in actual research. The challenge then is to provide effective preparation to researchers-intraining that expands their knowledge of qualitative methods and builds skills repertoire that enable them to actually perform like a qualitative methodologist.

A crucial point to make here is that reflective attention to tools and materials in the qualitative research classroom can help enhance students' learning, thereby hastening the development of 
methodological expertise. Such an attention to tools may run against the grain of qualitative research instructors, who are themselves generally less experienced CAQDAS users, and for whom CAQDAS is a mere technology, where the focus is on the technical features. We therefore need to take the discussion of CAQDAS to another level, moving the conversation beyond specific software to the larger issues of:

- How do we design our research projects with it?

- What are the implications of using CAQDAS?

Di Gregorio and Davidson (2008) take two positions which are particularly useful for our purposes here. The first is that the use of CAQDAS should be more fully integrated as a tool for qualitative methodology teaching. Second, they take a semi-formalized approach to the structuring of research project work in CAQDAS, creating the concept of a 'shell' in the software as an organizing framework which has potential at different stages of the research process. The shell consists of constructs created by the researcher using software functions and provides a frame for the management of work according to project designing enabling for instance wider and more complex interrogation of data [4].

\section{Blending technology and methodology}

In the few universities in Africa that have introduced teaching of CAQDAS as part of methodology training for their postgraduate students, there is an existing separation of qualitative methods training from qualitative software training. This can result, and indeed it does result, in disconnected technical and methodological learning curves [5]. Effective instruction in this regard requires skilled incorporation of a qualitative software package into the course syllabus. However, my experiences in including the teaching of qualitative data analysis software in a research methods course raise a number of issues. Feedback from my trainees suggests that the best way to learn qualitative data analysis requires exposure to both the theory of qualitative data analysis and hands-on practice analysing data. Trainees in my classes also indicated that if qualitative data analysis software were to be included in a methodology course, they would prefer to be provided an overall picture of the course right from the outset so that they can see how the software fits into the course. In addition, trainees viewed qualitative analysis as a separate phase to data collection. It did not occur to them that this should be an iterative process and that they could use the software to assist with the organization and integration of their literature review.

\section{Alternatives when teaching and learning CAQDAS}

\author{
One QDAS trainer once remarked: \\ More than use of the software \\ (anyone who has the users' guide \\ can learn how to use it), what else \\ must a CAQDAS workshop \\ include? [6]
}

The above remark shows that CAQDAS should not be limited to learning the use of the software's tools. Moreover, we need not believe that these programs are the panacea in qualitative analysis. In my part of the world, some qualitative researchers (albeit novice) use CAQDAS because these programs are fashionable, believing that the more tools they use the more complete their analysis. Others view qualitative data analysis in as much the same way as they do in a quantitative study believing it to be a separate phase to data collection.

Both of these are misconceptions of what the tools and programs are for. To use a CAQDAS is more than knowing how to import documents, code them and make reports [6]. It is not only to fit the software to the methodology the researcher is using or vice versa. It is also to know how your methodology relates to the tools the software has. My experience with researchers-in-training shows that they are eager for more information on the impact of computing on methods and can use the software in innovative and creative ways. In order to prevent a misuse of CAQDAS as well as strengthen the learning and teaching of qualitative research methods, we need to pay attention to three critical issues that I believe can guide training and capacity building among researchers-in-training to explore technological and methodological developments in qualitative software. When training or being trained we must bear in mind the following:

- Giving more information than developing skills - as an initial stage of training this can be regarded as an awareness raising exercise concerning issues of what ranges and types of software support qualitative data as well as questions to ask when choosing a CAQDAS package;

- Promoting critical thinking instead of mechanical thinking in the four learning tasks [7] that researchers-in-training will be engaged in during the course namely: approaches to qualitative data analysis; the nuts and bolts of the particular package; applying manual tasks used previously to the software; and computer literacy; 
- The possibility of analysing participants' own data- it should be one of the training workshop's goal that participants know how to analyse their own data rather than the common practice of giving participants the same documents to do exercise with a program. When participants are invited to bring their own data, it is easier for them to use the program when analyzing their interviews because they know what their research questions are and what they are looking for in the answers of their interviews.

\section{Collaborative working}

In a multi team environment in which social science researchers are increasingly working, researchers from different countries may be working together on a comparative project for instance. They need to share some of their data, their hypotheses and their analysis, and to move forward together using a shared theoretical framework. How does the QDAS technology enable partners on a project to benefit from the data and analysis of their colleagues who are working elsewhere, whilst preserving the integrity of their project, according to their preferences and as applicable to their particular context?

Some of the practical and methodological considerations involved in using the package collaboratively include paying attention to:

- Micro-processes involved in teamwork using a Qualitative Software Package

- Individual and institutional contexts for qualitative research software implementation.

For those whose research requires collaboration, the experience of teamwork data management can be problematic. Teams require systematic and often simultaneous access to data, but qualitative research is inherently messy. As Richards observed, most of us have a way of tolerating and dealing with our own style of mess. As such, most of us find others' messes a challenge and when it impedes understanding of the data, mess is a threat. Yet, the experience of team research has taught most survivors of the mess essential skills of data management [8].

According to Di Gregorio and Davidson, the electronic environment of software packages supports teamwork [4]. This means that the division of labour, among members working collaboratively on a particular research study, has to be planned in such a way so as to keep in mind the constraints and opportunities software packages bring with them. Along this line, Di Gregorio and Davidson advised that the project coordinator should have an extensive and comprehensive knowledge of the software package in use within a given research project in order to set up the shell of the electronic project (e-project, as they call it), to distribute tasks to the team members and to constantly evaluate the on-goring e-project.

The individual and institutional context of teaching and learning of qualitative research with QDAS is crucial if we are to comprehend the whole gamut of multi team environment for working collaboratively. While QDAS has been available for 25 years now, there are no current requirements, in Uganda (and indeed the sub-Saharan Africa) for doctoral supervisors or examiners to be trained in the use of QDA software. In Uganda, research training guidelines for postgraduate students inadvertently contribute to a false dichotomy between software and methods training in that the guidelines fail to emphasize the need for an integration of technology and methodology within postgraduate methods training. As a consequence, it is not unusual for university departments / supervisors either to send their postgraduate students for specialist training (by people involved in software training and consultancy) or to buy in specialists trainers in qualitative data analysis to teach specific software packages. A review of the continent wide methodology training workshop series conducted (or supposed to be) annually by two leading social science research institutes on the continent (i.e. Council for the Development of Social Science Research in Africa and the Organizations for Social Science Research in Eastern and Southern Africa) suggests that even now, relatively few researchers use computers software for QDA.

The above situation creates a dual barrier to teaching QDA. First is the lack of qualified instructors with both qualitative research experience and knowledge of computerized QDA and second, a previous lack of relevant computer software amenable to teach.

\section{Conclusion}

Discussions in this paper suggest that training students in the use of QDAS is not enough in and of itself. Those qualitative research instructors who integrate CAQDAS in their courses need to change their teaching practices if they are to be able to support the necessary changes in research practices. Having said that however, its also fair to say that there is still much to learn about how to use technology in the teaching and learning of qualitative research. There is no doubt that varying course structures may pose unique challenges but the ideas presented in this paper provide insight into the types of issues educators may face when integrating technology in research methods teaching. 


\section{References}

[1] P. Clarke, "Bridging the divides: Using and supporting NVivo in South Africa". Presented at conference on "Strategies in Qualitative Research: Methodological Issues and Practices in Using NVivo and NUD*ST" Institute of Education, University of London, $8^{\text {th }}-9^{\text {th }}$ May2003.

[2] J. Kikooma, "Software 'enabled' research? Fears, hopes and some 'new' vistas for social science research in Africa”. In F. Tusubira and N. Mulira (eds). Universities: Taking a leading role in ICT enabled human development, Phantom Solutions, Kampala, 2005.

[3] J. Davidson "NVivo as a tool for reading instruction: speculating on the possibilities - a research note", Qualitative Research Journal, 2003, 57-63.

[4] S. Di Gregorio and J. Davidson, Qualitative Research Design Users, Open University Press, Milton Keynes, 2008.

[5] L. Johnstone, "Software and method: reflections on teaching and using QSR NVivo in doctoral research”, International Journal of Social Research Methodology, 2006, 379-391.

[6] D. Carvajal, D. "The artisan's tools: critical issues when teaching and learning CAQDAS", Forum: Qualitative Social Research, 2002,. Retrieved from http//:www.qualitativeresearch.net/fqs-texte/2-02/2-02carvajal-e.html.

[7] S. Di Gregorio, "Using NVivo for you literature review." Presented at conference on "Strategies in Qualitative Research: Issues and Results from Analysis Using NVivo and NUD*ST" Institute of Education, University of London, $29^{\text {th }}-30^{\text {th }}$ September 2000.

[8] L. Richards, “ Qualitative teamwork: making it work”, Qualitative Health Research, 1999, 9(1), 710. 